\title{
Pemikiran Dakwah K.H. Fathul Mu'in Dg. Maggading: Gerakan Muhammadiyah Cabang Makassar 1960-1970
}

\author{
Syandri Syandri, ${ }^{1 *}$ Azwar Iskandar ${ }^{2}$ \\ 1,2Sekolah Tinggi Ilmu Islam dan Bahasa Arab (STIBA) Makassar, \\ Makassar - Indonesia
}

Article Information

Submission August 22, 2020

Revision September 10, 2020

Accepted September 15, 2020

Published October 01, 2020

\begin{abstract}
The Muhammadiyah da'wah movement has continued to develop from year to year, not only in the city of Makassar but has also penetrated remote villages. In Makassar itself, this early movement was headquartered on Banda Street (now Jl. Banda), a place belonging to Daeng Tawiro.This research aims to know: (1) da'wah challenges faced by Muhammadiyah regional leader in 19601970 period; and (2) strategic programs of Muhammadiyah Makassar in dealing with da'wah problems. This research is a qualitative descriptive study with library research technique using historical and sociological approaches. The results showed: first, K.H. Fathul Mu'in Dg. Maggading as Chairman of Muhammadiyah Makassar period 1960-1966, faced three major challenges of da'wah at the beginning of his leadership period: (a) the growth of the PKI movement, (b) the dissolution of the Masyumi Party, and (c) paralysis of the Muhammadiyah movement on various lines; Secound, K.H. Fathul Mu'in Dg. Maggading as the pinning of Makassar Muhammadiyah Branch took several strategic steps as an effort to improve among the people, namely: (a) consolidation, (b) stabilization, and (c) promoting development.
\end{abstract}

Keywords: $\quad$ K.H. Fathul Mu'in Dg. Maggading; da'wah; thought; Muhammadiyah; Makassar

Gerakan dakwah Muhammadiyah terus mengalami perkembangan dari tahun ke tahun, tidak hanya di kota Makassar tetapi juga telah menembus pelosok-pelosok perkampungan. Di Makasar sendiri Gerakan awal ini bermarkas di Banda Street (kini Jalan Banda), sebuah tempat milik Daeng Tawiro. Penelitian ini bertujuan untuk mengetahui: (1) tantangan dakwah yang dihadapi pimpinan daerah Muhammadiyah pada masa 1960-1970; dan (2) langkah-langkah strategis Muhammadiyah Cabang Makassar dalam menghadapi masalah dakwah. Penelitian ini merupakan penelitian deskriptif kualitatif dengan teknik studi pustaka (library research) menggunakan pendekatan historis dan sosiologis. Hasil penelitian menunjukkan: Pertama, K.H. Fathul Mu'in Dg. Maggading sebagai Ketua Muhammadiyah Makassar Cabang periode tahun 1960-1966, menghadapi tiga tantangan pokok dakwah di awal periode kepemimpinanya: (a) pertumbuhan Gerakan PKI, (b) bubarnya Partai Masyumi, dan (c) kelumpuhan gerakan Muhammadiyah di berbagai lini; Kedua, K.H. Fathul Mu'in sebagai pempinan Cabang Muhammadiyah Makassar melakukan beberapa langkah strategis sebagai upaya perbaikan di tengah-tengah umat, yaitu: (a) konsolidasi, (b) stabilisasi, dan (c) menggalakkan pembangunan.

Kata Kunci: $\quad$ K.H. Fathul Mu'in Dg. Maggading; dakwah; pemikiran; Muhammadiyah; Makassar

*Korespondensi Penulis: Syandri Syandri, email: syandri@stiba.ac.id, Jl. Inspeksi PAM, Manggala, Makassar, Sulawesi Selatan 90234.

Copyright (C) 2020 Syandri Syandri, Azwar Iskandar 


\section{Pendahuluan}

Masuknya Muhammadiyah di Sulawesi Selatan bermula dari kota Makassar, ditandai dengan diresmikannya Muhammadiyah Cabang Makassar pada tanggal 2 Juli 1926 melalui keputusan Hofd Bestuur nomor 51/1926 sebagai cabang pertama di luar Jawa dan Sumatera yang sebelumnya hanya berstatus Muhammadiyah Goup Makassar (Alwi, 2013).

Kehadiran Muhammadiyah Cabang Makassar tidak lepas dari upaya dakwah yang dilakukan oleh seorang pedagang kain asal Madura yaitu Mansur al-Yamani. Sebelum ke Makassar, ia tercatat sebagai anggota Muhammadiyah Cabang Surabaya dan sangat aktif berdakwah dalam kesatuan muballig Muhammadiyah. Ketika hijrah ke Makassar Mansur alYamani terus menjalankan kegiatan dakwahnya (Darmawijaya \& Abbas, 2014). Pada masa ini, setidaknya ada empat pokok permasalahan yang dihadapi gerakan dakwah Muhammadiyah, dari masyarakat awam, golongan bangsawan, golongan yang buta terhadap agama, dan pemerintah kolonial (Hamid et al., 2015).

Sebagai gerakan reformis yaitu gerakan yang menggunakan organisasi sebagai alat perjuangannya dan berusaha memurnikan Islam serta membangun kembali Islam dengan pikiranpikiran baru, sehingga Islam dapat mengarahkan dan membimbing umat manusia dalam kehidupan mereka (Pasha \& Darban, 2000). Muhammadiyah berkeyakinan bahwa kemunduran umat Islam terjadi karena kehidupan umat Islam sudah jauh dari konsep Islam yang sebenarnya (Elhady, 2017). Kehidupan umat Islam sangat dipengaruhi oleh takhayul, bid'ah, dan khurafat. Kemajuan umat Islam hanya bisa dicapai apabila umat Islam betul-betul mengamalkan ajaran Islam yang murni, yaitu ajaran Islam yang bersumber pada Al-Qur'an dan sunah Rasulullah yang sahih (Noer, 1996).

Dalam perjalanan dan perkembangannya, Muhammadiyah Cabang Makassar mengalami perputaran roda kepemimpinan. Tampuk kepemimpinan berjalan silih berganti untuk mencapai tujuan dan cita-cita Muhammadiyah. Di antara tokoh pimpinan yang terkenal dan memiliki sumbangsih cukup signifikan dalam pengembangan Muhammadiyah khususnya di pertengahan abad XX adalah K.H. Fathul Muin Dg. Maggading. Seorang tokoh gerakan Muhammadiyah Cabang Makassar yang menjabat sebagai ketua cabang selama sepuluh tahun (1960-1970).

Dalam menjalankan kepemimpinannya di Cabang Muhammadiyah, K.H. Fathul Muin Dg. Maggading menghadapi banyak tantangan yang harus dilalui. Berkat kesungguhannya pada masa kepemimpinannya, dapat dikatakan bahwa Muhammadiyah secara keorganisasian kembali menguat, demikian halnya dari sisi finansial organisasi yang semakin matang. Berbagai jenis usaha ditumbuhkan, demikian halnya dengan menghidupkan kembali institusi-institusi organisasi. Di antara tantangan berat dakwah yang dihadapi oleh K.H. Fathul Muin Dg. Maggading adalah di akhir tahun 1967-1969 yaitu ketika Walikota Makassar, Mohammad Dg. Patompo, melakukan program pemberantasan Kemiskinan, Kebodohan, dan Kemelaratan atau yang dikenal dengan istilah 3K. Program ini terhambat 
karena kekurangan dana. Oleh karena itu, Walikota mencari jalan keluar dengan membolehkan dan mengumpulkan dana non-konvensional berupa pajak perjudian dari Lotere Totalisator (Lotto) (Handayani \& Bosra, 2019). Melihat kondisi menyedihkan di mana masyarakat telah berubah (paradigma berfikir), malas bekerja keras karena hanya menunggu hasil dari Lotto, dan diperparah dengan hilangnya nilai-nilai syariat yang mengharamkan perjudian, para ulama Makassar termasuk di antaranya K.H. Fathul Mu'in Dg. Maggading, menentang keras kebijakan ini (Salbu, 2012).

Pola pemikiran dakwah dan perjuangan organisasi Muhammadiyah dan pimpinannya dalam mencapai tujuannya sesungguhnya sangat penting untuk dikaji dan didalami. Sebagai sebuah gerakan pembaharuan, sepak terjang Muhammadiyah di bawah kepemimpinan dan pengaruh tokoh sentral yang silih berganti sesungguhnya dapat menjadi pelajaran berharga bagi gerakan pembaharuan Islam, khususnya di wilayah Sulawesi Selatan, di mana organisasi ini dinilai dapat terus aktif dan berkembang dengan baik di kalangan masyarakat Sulawesi Selatan hingga kini (Abbas et al., 2014). Beberapa kajian dan penelitian terdahulu telah mengkaji gerakan dan geliat organisasi Muhammadiyah di Sulawesi Selatan.

Darmawijaya dan Abbas meneliti tentang sejarah masuknya Muhammadiyah ke Makassar pada tahun 1926. Dalam penelitiannya, Darmawijaya dan Irwan Abbas menyebutkan bahwa berkembangnya Muhammadiyah di Sulawesi Selatan tidak dapat dilepaskan dari beberapa faktor, yaitu: Muhammadiyah tidak terlibat politik praktis; Muhammadiyah memiliki kemampuan organisasi yang baik; Muhammadiyah konsisten sebagai gerakan pembaharuan; Muhammadiyah didukung oleh kaum pedagang, para haji, kaum bangsawan dan sebagian keturunan Arab; kemampuan Muhammadiyah dalam mengembangkan amal usahanya.

Risfaisal, Sriwahyuni dan Rosnatang mengkaji tentang eksistensi gerakan sosial Muhammadiyah di era modernisasi di tengah kehidupan berbangsa dan bernegara pada masyarakat di Kelurahan Lakawan Kecamatan Anggeraja Kabupaten Enrekang. Hasil penelitian menunjukkan bahwa Muhammadiyah dapat mengimplemnetasikan ajaran-ajaran Islam sebenarnya sesuai dengan Al-Qur'an dan Sunah dan dapat menghilangkan tradisi-tradisi yang mencampurbaurkan antara ajaran Islam dan aqidah dengan yang bukan akqidah (musyrik) Islam di tengah kehidupan berbangsa dan bernegara (Risfaisal \& Rosnatang, 2017).

Arif, Asfitah, Patahuddin, dan Mustari Bosra meneliti tentang latar belakang didirikannya Muhammadiyah di Kabupaten Soppeng. Hasil penelitian ini menyatakan bahwa Muhammadiyah didirikan di Kabupaten Soppeng dilatarbelakangi oleh alasan untuk melakukan perubahan di dalam diri umat Islam itu sendiri untuk meninggalkan kebiasaan-kebiasaan nenek moyang yang telah lama dianutnya, dan menyakinkan masyarakat bahwa ajaran Islam adalah satu-satunya landasan kepribadian dan ketertiban bersama untuk kebahagiaan dunia dan akhirat. Perkembangan Muhammadiyah di Kabupaten Soppeng juga dapat dilihat dari kegiatan-kegiatan yang dilakukannya mulai 
1930-1985. Mulai dari sekolah yang didirikan, konferensi Muhammadiyah Sulawesi Selatan Tenggara yang diadakan di Kabupaten Soppeng maupun kegiatan-kegiatan lainnya. Peran Muhammadiyah di Kabupaten Soppeng, dapat dilihat mulai dari bidang dakwah dan pemurnian Islam, bidang pendidikan dan sosial, hingga bidang politik. Hal ini memberikan pengaruh besar terhadap masyarakat Soppeng, di mana dalam setiap kegiatannya bertujuan untuk membimbing dan memberikan pemahaman kepada masyarakat tentang arti penting pengajaran Islam. (Arif et al., 2016)

Alwi menulis tentang gerakan dakwah Muhammadiyah di Sulawesi Selatan. Hasil penelitian ini mengungkapkan bahwasanya Muhammadiyah di Sulawesi Selatan tidak bisa lepas dari misi utamanya yaitu sebagai gerakan tajdid dalam dakwah yang berimplikasi pada pentingnya aktualisasi aktivitas anggota untuk lebih giat dan berkomitmen mengiplementasikan tajdid melalui gerakan dakwah, terutama dakwah jama'ah di tengah-tengah masyarakat. Berkenanan dengan itu, direkomendasikan agar Pimpinan Wilayah Muhammadiyah Sulawesi Selatan secara kolektif bersama majelis/lembaga, organisasi otonom sampai ke tingkat bawah, yakni Pimpinan Daerah, Pimpinan Cabang dan Pimpinan Ranting untuk senantiasa mengadakan ravitalisasi tajdid sebagai gerakan dakwah dalam rangka penguatan program persyerikatan, terutama menyangkut aspes ideologis, pemikiran, organisasi, kepemimpinan, dan amal-amal usaha. (Alwi, 2013)

Hamid, Jalaluddin, Nurdin dan Achmad meneliti tentang sejarah perjalanan Muhammadiyah di Makassar beserta peristiwa-peristiwa yang membersamai perkembangan dakwah Muhammadiyah sejak berdirinya di Sulawesi Selatan dalam buku Matahari Pembahari di Serambi Madinah menelusuri tapak sejarah Muhammadiyah di Kota Makasaar. Hasil penelitian buku ini menjelaskan sejarah panjang perjalanan organisasi Muhammadiyah di Makassar dan secara khusus mengangkat ketokohan para pimpinan Muhammadiyah cabang Makassar dari awal sampai tahun 2015, termaksud di dalamnya adalah K.H. Fathul Muin Dg Maggading (Hamid et al., 2015).

Nursalam dan Suardi, meneliti tentang interaksi keberagamaan Muhammadiyah di kota Makassar. Hasil penelitian menunjukkan bahwa untuk menjadi dai Muhammadiyah, harus memenuhi syarat yaitu: (1) merupakan kader, (2) aktif dalam organisasi, (3) rekomendasi dari Pimpinan Ranting atau Cabang, (4) lulus seleksi administrasi, (5) lulus tes kemampuan membaca Al-Qur'an dan tes kemampuan melakukan ceramah atau khutbah.

Kompetensi yang harus dimiliki oleh dai Muhammadiyah yaitu (1) memahami Al-Qur'an dan hadis, (2) memiliki ilmu pengetahuan dan pendidikan, (3) mengikuti pelatihan. Bentuk model dai Muhammadiyah terbagi menjadi tiga bentuk yaitu model dakwah serius, model dakwah humoris dan model dakwah gabungan serius dan humoris. Materi dakwah Muhammadiyah mencakup tujuh materi yaitu akidah, akhlak, tarikh, kajian umum, kajian khusus dan Masail fiqhiyyah. Peran dai meliputi penguasaan media sosial, regenerasi dai, pemahaman peta 
dakwah, efisiensi waktu, melakukan kajian dan membaca (Nursalam, 2017).

Meskipun kajian atau penelitian-penelitian tersebut di atas telah mengkaji sejarah gerakan Muhammadiyah di sekitar wilayah Sulawesi Selatan, akan tetapi kajian atau penelitian terkait sepak terjang tokoh pemimpin organisasi Muhammadiyah secara pribadi atau individu, belum banyak dilakukan. Sejauh pengamatan penulis, studi tentang pemikiran dan pola gerakan dakwah dan perjuangan K.H. Fathul Muin Dg. Maggading sebagai salah satu pimpinan dalam sejarah Muhammadiyah di Makassar belum pernah dilakukan. Oleh karenanya, penelitian ini dilakukan dengan tujuan untuk: (1) mengetahui masuknya pengaruh organisasi Muhammadiyah ke kota Makassar; (2) mengetahui tantangan dakwah yang dihadapi pimpinan daerah Muhammadiyah pada masa 1960-1970; dan (3) mengetahui langkah-langkah strategis Muhammadiyah Cabang Makassar dalam menghadapi masalah dakwah.

\section{Metode}

Penelitian ini merupakan penelitian deskriptif kualitatif (library research) (Creswell, 2010). Penelitian ini menggunakan pendekatan multidisipliner (Rohmatika, 2019) yaitu: (1) pendekatan historis, yaitu penelaahan serta sumbersumber yang berisi informasi mengenai masa lampau dan dilaksanakan secara sistematis, untuk mengetahui dan memahami serta membahas secara mendalam tentang seluk-beluk atau hal-hal yang berhubungan dengan topik kajian, baik berhubungan dengan ajaran, sejarah maupun praktik-praktik pelaksanaannya secara nyata dalam kehidupan sehari-hari, sepanjang sejarahnya (Haryanto, 2017); (2) pendekatan sosiologis, yaitu kajian yang menjadikan masyarakat sebagai objek kajian yang dilihat dari sudut hubungan antara manusia dan proses yang timbul dari hubungan manusia dalam masyarakat (Rifa'i, 2018). Penelitian ini menggunakan data sekunder yang diperoleh melalui teknik studi pustaka dari buku, jurnal, penelitian dan laporanlaporan yang terkait dengan topik utama penelitian yaitu sejarah dan pergerakan K.H. Fathul Muin Dg. Maggading di masa kepemimpinannya.

\section{Hasil dan Pembahasan}

Membicarakan tentang kehadiran Muhammadiyah di Sulawesi Selatan, dimulai dari kedatangan Mansur al-Yamani di Makassar pada sekitar tahun1923. Ketika itu, al-Yamani dikenal sebagai seorang pedagang batik. Dia membuka toko di 'Tasaartraat' (sekarang jalan Nusantara). Al-Yamani dilahirkan di Sumenep, Madura, pada sekitar tahun 1894. Ayahnya adalah seorang Madura keturunan Arab (Suprapto, 2018). Di Sumenep, al-Yamani kecil belajar agama pada ayahnya sendiri dan kepada beberapa orang kiai, di samping belajar di sekolah pemerintah. Sebelum hijrah ke Makassar, al-Yamani muda menetap di Surabaya, ketika Muhammadiyah Cabang Surabaya terbentuk, dia menjadi salah seorang anggotanya, sebagai anggota Muhammadiyah, dia aktif belajar kepada kiai Haji Mas Mansur, voorsitter (ketua) Muhammadiyah Cabang Surabaya (Bosra, 2015)

Berbekal ilmu agama dan ke-Muhammadiyah-an yang diperolehnya itu, sejak masih di Surabaya, al-Yamani sudah menjadi Mubalig 
Muhammadiyah. Setelah hijrah ke Makassar, dia meneruskan kegiatan dakwahnya, di samping profesinya sebagai pedagang. Untuk melaksanakan aktivitas dakwahnya di Makassar, al-Yamani menjalin hubungan dengan para pengurus dan anggota organisasi keagamaan lokal di Makassar, yang pada umumnya juga pedagang. Setelah lebih kurang tiga tahun, al-Yamani memperkenalkan Muhammadiyah kepada para pengurus dan anggota Shiratathal Mustaqim, sebuah organisasi Islam di Makassar. Sampailah pada satu klimaks yaitu ketika beberapa orang pengurus dan anggota Shirathal Mustaqim berkehendak untuk melebur organisasinya ke dalam Persyarikatan Muhammadiyah dengan jalan membentuk cabang Muhammadiyah di Makassar. Keinginan itu tentu disambut baik oleh hoofdbestuur (Pimpinan Pusat) (Chakim, 2017).

Setelah lebih kurang tiga tahun, al-Yamani memperkenalkan Muhammadiyah kepada para pengurus dan anggota Shirathal Mustaqim. Alhasil, ada beberapa orang pengurus dan anggota Shirathal Mustaqim yang menyatakan diri keluar dari Shirathal Mustaqim dan kemudian berkeinginan untuk mendirikan Muhammadiyah Cabang Makassar. Mereka itu adalah Haji Abdullah dan kawan-kawannya (Ramly \& dkk, 2006). Mengetahui akan adanya keinginan dari kubu Haji Abdullah untuk bergabung dan mendirikan Muhammadiyah, maka pada malam 15 Ramadhan 1344 H, yang bertepatan dengan 27 April 1926, diadakan rapat pembentukan perkumpulan Muhammadiyah di Makassar (Bosra, 2008).

Hal lain yang juga menjadi keputusan rapat ialah Muhammadiyah Group Makassar yang baru terbentuk itu akan mengutus Mansur alYamani ke Yogyakarta untuk melaporkan kepada Hoofdbestuur agar segera datang meresmikan dan memberikan petunjukpetunjuk dan bimbingan lebih lanjut (Huda, 2019). Berselang lebih kurang satu bulan setelah terbentuknya, Muhammadiyah Group Makassar, bertolaklah Mansur al-Yamani ke Yogyakarta. Sambil berbelanja untuk keperluan tokonya, dia pun segera menjalankan amanah yang dibebankan kepadanya, yakni melapor dan memohon kedatangan Hoofdbestuur Muhammadiyah ke Makassar (Handayani \& Bosra, 2019)

Pada akhir tahun 1926 M, status Muhammadiyah Makassar berubah dari status Group (Ranting) menjadi status Cabang. Tahun 1927 M, Persyarikatan Muhammadiyah Cabang Makassar mulai melakukan pengembangan dakwah baik dalam kota Makassar maupun di luar Makassar. Daerah pertama yang berhasil mendirikan Persyarikatan Muhammadiyah adalah Rappang pada tahun 1927 M dan tahuntahun berikutnya Persyarikatan Muhammadiyah hampir merata di wilayah Sulawesi Selatan (Adiansah et al., 2016).

Dalam kota Makassar sendiri, tahun 1928 M telah terbentuk empat group (ranting) Muhammadiyah yakni; Muhammadiyah Group Bontoala, group ini dipimpin oleh Sulaiman Daeng Matutu, Muhammadiyah Group Kampong Pisang, dipimpin oleh Daeng Mamuji, Sabang Daeng Ngago dan Bahar, Muhammadiyah Group Mariso, dipimpin oleh Haji Tuppu Daeng Palallo, dan Muhammadiyah Group Lariangbangi yang dipimpin oleh Daeng Masino (Wildan, 2015) 
Pada tahun 1932 M, Persyarikatan Muhammadiyah Cabang Makassar mendapat amanah untuk menjadi panitia Kongres Muhammadiyah XXI sesuai dengan permintaan utusan Muhammadiyah Cabang Makassar ketika menghadiri Kongres Muhammadiyah XX di Yogyakarta (Sukarta, 2018). Kepanitian ini merupakan salah satu bukti bahwa Muhammadiyah di Makassar telah memiliki basis yang kuat dalam kehidupan masyarakat, karena tanpa dukungan masyarakat adalah suatu hal yang sangat gegabah dalam menerima amanah ini (Darmawijaya, 2007)

\section{Tantangan Dakwah di Awal Kepemimpian}

K.H. Fathul Mu'in Dg. Maggading adalah seorang dai sekaligus pengusaha yang sukses. Sebelum menjabat sebagai pimpinan Cabang Muhammadiyah Makassar, beliau adalah pebisnis yang berhasil. Dia lalu meninggalkan semua aktivitas bisnisnya untuk lebih memfokuskan diri mengembangkan organisasi Muhammadiyah khususnya setelah dipilih secara aklamasi untuk memimpin Muhammadiyah Cabang Makassar. Perjuangan K.H. Fathul Mu'in dalam kepemimpinananya, tidak terlepas dari berbagai macam tantangan dan kondisi yang terjadi di era tersebut. Dalam rentang tahun 1960-1966, K.H. Fathul Mu'in menghadapi tiga tantangan pokok dakwah di awal periode kepemimpinanya sebagai berikut:

\section{Pertumbuhan Gerakan PKI}

Pada Pemilihan Umum (Pemilu) pertama tahun 1955, Parta Komunis Indonesia (PKI) memperoleh suara 39 kursi dari 157 kursi yang diperebutkan oleh organisasi politik peserta
Pemilu. Hasil Pemilu tersebut menunjukkan eksistensi pengikut komunisme di Indonesia pada tahun 1955 yang berjumlah sekitar 15 juta jiwa atau sekitar 15,2 persen dari seluruh rakyat Indonesia.

Pada tahun enam puluhan, keadaan perekonomian di Indonesia semakin memburuk, kehidupan rakyat semakin sulit. Kondisi ekonomi dan kehidupan masyarakat yang demikian, menjadi persemaian subur semakin melebarnya pengaruh PKI yang datang kepada buruh tani dengan janji akan membagi tanah.

Suasana antagonis yang mewajahkan pertentangan dan curiga-mencurigai serta kebencian terhadap orang miskin yang diistilahkan sebagai kaum proletar, dihidupkan dalam masyarakat untuk mempermatang situasi revolusioner. Mereka pun berusaha dan berhasil menyusup ke tubuh alat-alat kekuasaan negara dan berhasil mempengaruhi sebagian dari mereka terutama di Jawa dan Jakarta.

Kemudian PKI dalam perjalanan sejarah, untuk kedua kalinya melakukan pengkhianatan terhadap bangsa dan negara. Belum lagi terlupakan kebiadaban mereka menyembelih alim ulama, pimpinan nasional pada pemberontakan di Madiun tahun 1948, kebiadaban itu diulang lagi dengan membantai putera-puteri terbaik bangsa ini, pimpinan Angkatan Darat, perwira-perwira tinggi yang diperkirakan akan menghalangi gerakan pengkhianatan mereka. Kebiadaban PKI yang telah dua kali dipertontonkan itu menyebabkan amarah rakyat meluap. Rakyat bangkit bersama-sama dengan ABRI melakukan pembalasan menumpas PKI dan seluruh pendukungnya. Mereka melahirkan 
tuntutan yang terkenal dengan Tiga Tuntutan Rakyat (Tritura), salah satu dari padanya ialah tuntutan agar PKI dan organisasi-organisasi pendukungnya dibubarkan dan dinyatakan terlarang di seluruh Indonesia.

Setelah adanya tuntutan ini, kondisi semakin memburuk. Sampai akhir tahun 1965, tidak ada tindakan pihak militer untuk mencegah meluasnya pembunuhan dan pengejaran terhadap orang-orang PKI. Pada tanggal 1 Oktober 1965, aksi kemarahan massa berlanjut dan berubah menjadi penjarahan milik orang-orang Tionghoa, dan penghancuran rumah orang Jawa.

Penyuaraan anti-PKI meluas hampir ke seluruh Indonesia termaksud di Makassar dan sekitarnya. Pengrusakan rumah orang-orang Jawa terjadi di Balang Boddong Makassar. Di daerah ini bermukim orang-orang Jawa sejak zaman revolusi. Kasus lain dialami oleh Aminuddin Patta Lolo, seorang aktivis pemuda rakyat, pada awal penangkapannya tanggal 15 Oktober 1965, ia ditempatkan di Komtabes Makassar. Sel-sel sudah penuh dengan tahanan, bersamaan dengan itu terjadi rapat akbar yang dihadiri 22 ormas di lapangan Karebosi menuntut pembubaran PKI. Kemudian, tempat penahanan yaitu sel Komtabes Makassar didemo oleh KAMMI, KAPPI dan Pemuda Anshor. Para demonstran menerobos masuk sel-sel, tetapi para tahanan itu telah diamankan oleh aparat dan dibawa ke tahanan Kodim 1408 Makassar untuk menghindari keberingasan massa.

Aksi kemudian berkembang di Bone. Andi Mappa, Ketua PKI, Igoo Garnida Heri Erianto, Sekjen PKI dan Kalwater, Ketua SOBSI Bone, seorang keturunan Belanda, juga sebagai Kepala
Kantor Lembaga Pemasyarakatan (Lapas), tewas dibunuh oleh massa. Aksi massa di Bone yang berlangsung secara spontan ini kemudian menjalar sampai ke penjara dan Kodim/Polres tempat orang-orang PKI meminta perlindungan.

Pembunuhan terjadi di Kodim Bone. Kurang lebih ratusan warga sipil yang berasal dari Jawa ikut menjadi korban. Mereka pada umumnya karyawan Pabrik Gula Arasoe yang didatangkan dari Jawa untuk memenuhi kebutuhan tenaga profesional di pabrik tersebut (Ahmad, 2008). Pada mulanya, mereka ditempatkan di penjara Kodim karena asrama mereka belum selesai dibangun. Akan tetapi setelah G30S meletus, mereka dibantai karena sentimen ras Jawa yang meningkat sekitar tahun 1960-an. Para korban pembantaian massal kemudian dikubur secara massal di sebuah sumur di Kampung Colodo Bone. Menurut data yang terpercaya, pembantaian anggota dan yang dianggap PKI di Bone adalah yang terbesar ke-3 setelah Jawa dan Aceh. Jumlah yang dibantai di Bone adalah 350 jiwa. Gejolak seperti ini juga terjadi di beberapa daerah, seperti Bantaeng, Wajo, Sidrap dan lainnya.

Secara keorganisasian, Muhammadiyah cepat merespon situasi dan kondisi yang berkembang saat itu, khususnya yang barkaitan dengan masalah gerakan PKI yang terus merajalela. Pengurus Komando Kesigapan Angkatan Muda (Kokam) dibentuk dengan tujuan membentengi generasi muda Indonesia khususnya umat Islam dari pengaruh buruk PKI. Angkatan pertama Pengurus Kokam diketuai oleh Abdul Kadir Sarro dan wakil M. Ja'far Tinri. Adapun Kokam Kotamadya Ujung pandang yang menjadi 
pusat kegiatan operasi diketuai oleh Tajuddin Ibrahim. Rumusan perjuangannya sederhana yaitu "Menghancurkan sampai lenyap GespatuPKI adalah termaksud ibadah."

K.H. Fathul Mu'in Dg. Maggading sendiri yang pada masa itu menjabat sebagai ketua Cabang Muhammadiyah Makassar juga turut andil melakukan perlawanan terhadap agresivitas PKI. Usman Maesar adalah salah seorang penggerak "penggayangan PKI" di Bantaeng yang juga merupakan murid dekat kiai menyampaikan bahwa K.H. Fathul Mu'in saat itu terus mengobarkan semangat pemuda-pemuda $\mathrm{Mu}-$ hammadiyah untuk menghentikan gerak laju PKI, apalagi setelah pengkhianatan-pengkhianatan yang dilakukan terhadap negeri ini khususnya umat Islam.

Kondisi buruk ini digambarkan oleh K.H. Fathul Mu'in Dg. Maggading sebagai konsekuensi berkuasanya Sukarno dengan melalui jalan-jalan yang bertentangan dengan Undang-Undang Dasar (UUD) RI, sehingga memberikan jalan yang sangat baik bagi golongan-golongan yang hendak memperalat agama menghancurkan ajaran Islam umumnya dan filsafat Pancasila pada khususnya. Kiai melanjutkan, "Sejarah ini membuktikan bahwa Sukarno memberikan peluang yang sangat besar bagi pertumbuhan PKI dan golongan-golongan yang telah pernah ikut menghalalkan Nasakom." (Dg. Maggading, 1967)

Pada masa-masa sulit ini, sebagai veteran perjuangan kemerdekaan dan tuntutan agama untuk melindungi diri, K.H. Fathul Mu'in Dg. Maggading melalui Kokam senantiasa melakukan persiapan menghadapi segala tantangan yang mungkin akan muncul dari pergerakan PKI.
Oleh sebab itu, bersama dengan ABRI, kiai memobilisasi pemuda Muhammadiyah khususnya di wilayah Makassar untuk melakukan penggayangan PKI.

\section{Bubarnya Masyumi}

Kondisi kedua yang dihadapi pada awal kepemimpinan adalah dibubarkannya Masyumi. Partai Majelis Syuro Muslimin Indonesia atau yang disingkat Masyumi lahir di Yogyakarta pada tanggal 7 November 1945 sebagai respon umat Islam terhadap imbauan pemerintah melalui pengumuman tanggal 3 November 1945 yang mengajak rakyat Indonesia untuk mendirikan partai sebagai wadah penyaluran aspirasi politik Imbauan tersebut ditandatangai oleh Wakil Presiden RI, Mohammad Hatta, dan diulangi lagi pada tanggal 3 November 1945.

Berdirinya partai politik tersebut diputuskan dalam Kongres Muslim Indonesia di Madrasah Mu'allimin Muhammadiyah Yogyakarta. Kongres tersebut mengikrarkan: 1) Masyumi adalah satu-satunya partai politik Islam di Indonesia. 2) Bahwa Mahsyumilah yang akan memperjuangkan nasib umat Islam Indonesia. 3) Memperkuatpersiapan umat Islam untuk berjihad fi sabilillah dalam melawan segala bentuk penjajahan. 4) Memperkuat pertahanan Negara Indonesia dengan menyusun Barisan Sabilillah di daerah-daerah. 5) Memilih Dr. Soekiman sebagai ketua, dan wakil ketua masing masing Abikusno dan Wali al Fatah. Ketiga orang itu diberi mandat untuk menyusun kepengurusan Masyumi (Siregar, 2013).

Ikrar ini menunjukkan bahwa umat Islam di Indonesia tidak mengakui keberadaan partai 
Islam selain Masyumi. Sifat keanggotaan Partai Masyumi, selain perorangan juga organisasi. Dalam kedudukannya sebagai anggota istimewa, Muhammadiyah merupakan salah satu anggota istimewa dalam Partai Masyumi. Dengan begitu, Muhammadiyah memiliki hak untuk memberikan nasihat atau saran kepada Partai Masyumi.

Di bagian timur Indonesia khususnya Makassar, Partai Masyumi berhasil dibentuk pada akhir tahun 1949, empat tahun setelah berdirinya Partai Masyumi di Yogyakarta walaupun awalnya dengan status komisariat. Mohammad Noor, M. Ismail Nupu dan Ahmad Mangkarasausu adalah formatur bagi pembentukan Partai Masyumi di Makassar.

Awal tahun 1950 terbentuklah Dewan Pimpinan Wilayah dengan daerah tugas meliputi seluruh Sulawesi yang waktu itu masih satu provinsi. Dalam kepengurusannya, Dewan Pimpinan Wilayah Partai Masyumi tersebut diduduki beberapa orang Muhammadiyah yakni: (1) Muhammad Noor, Ketua Muhammadiyah Cabang Bulukumba sebagai Ketua Dewan Pimpinan Wilayah. (2) Abdul Wahab Radjab, Ketua Muhammadiyah Ranting Bone-Limbung sebagai sekretaris. (3) Haji Andi Sewang Daeng Muntu konsul Muhammadiyah daerah Sulawesi Selatan sebagai anggota. (4) Haji Muhammad Aqib dari Pimpinan Daerah Muhammadiyah Sulawesi Selatan sebagai Anggota. (5) Ramlah Azis, Ketua Aisiyah Daerah Sulawesi Selatan sebagai anggota dan merangkap sebagai Ketua Muslimat Masyumi wilayah Sulawesi. (6) Abbas Daeng Mallawa dari pimpinan Muhammadiyah bagian Majelis Pemuda sebagai anggota.

Dalam perjalannya, interaksi Masyumi dengan partai politik dan Presiden Sukarno, dipenuhi dinamika, baik secara internal maupun eksternal. Hubungan Masyumi dengan Presiden Sukarno pernah mengalami hubungan yang harmonis, terutama pada masa revolusi. Hubungan ini sedikit demi sedikit mengalami pergeseran hingga menjurus pada konflik.

Hubungan Masyumi-Sukarno semakin buruk khususnya ketika Presiden Sukarno ingin mengubur partai politik pada bulan Oktober 1956 dan Konsepsi Presiden tahun 1957. Konflik ini terus berlanjut hingga masa Demokrasi Terpimpin. Dekrit Presiden 5 Juli 1959 semakin memperkuat kekuasaan Sukarno. Namun di sisi lain, semakin melemahkan posisi dan peran Partai Masyumi, bahkan peran politik Masyumi diakhiri Sukarno melalui Keputusan Presiden No. 200 tahun 1960. Di antara faktor yang menyebabkan dibubarkannya Masyumi: 1) Sukarno ingin merealisasikan pemikiran dan obsesinya yang sudah lama terkubur, terutama mengenai partai politik, demokrasi dan revolusi. 2) Adanya konflik berkepanjangan antara Sukarno dengan Masyumi. Konflik itu mulai muncul ketika Perdana Menteri, M. Natsir, menolak usul Presiden Sukarno tentang cara penyelesaian Irian Barat.

K.H. Fathul Mu'in Dg. Maggading berpendapat bahwa bubarnya Masyumi telah membawa keadaan baru pada situasi politik Indonesia yang oleh Seokarno dan seluruh partai penyokongnya membelokkan politik bebas ke arah lain. Menurutnya, hal ini membawa akibat yang sangat merugikan perjuangan umat Islam, di mana pimpinan-pimpinan Islam yang "radikal" dan revolusioner disudutkan sehingga kebanyakan di antara mereka lumpuh. Bukan hanya sampai di situ, yang lebih parah 
menurutnya sebagian pimpinan Masyumi telah meninggalkan umat.

\section{Kelumpuhan Muhammadiyah}

Perjalanan awal kepemimpinan K.H. Fathul Mu'in Dg. Maggading sebagai Ketua Cabang Muhammadiyah Makassar cukup sulit, di mana organisasi mengalami banyak masalah di berbagai lini, terkhusus setelah dibubarkannya Masyumi oleh Presiden Sukarno. Kiai mengatakan bahwa Muhammadiyah sebagai pelopor pembangunan dan anggota istimewa Masyumi mengalami kenyataan yang pahit. Sebagian besar pimpinannya menggabungkan diri kepada Masyumi sehingga praktis segala usaha Muhammadiyah berantakan. Tinggallah orang-orang yang tidak mengerti Muhammadiyah, baik jiwa ataupun cara gerak, dan bagaimana memeliharanya.

Dalam kondisi seperti ini, menurutnya dakwah islamiyah sebagai lapangan vital perserikatan ditinggalkan. Pengajaran dan pendidikan sebagai alat untuk membangunkan jiwa "reformasi" Islam, tidak berhasil. Tujuan pendidikan yaitu agar lahir generasi yang berguna bagi bangsa dan agama, tidak lagi menjadi perhatian para guru yang memimpin sekolahsekolah.

Bahkan sangat disayangkan, usaha-usaha sosial, di antaranya pemeliharaan anak yatim, telah dijadikan oleh sebagian oknum untuk memperkaya diri (mencari hidup dalam Muhammadiyah). Gedung-gedung dan tanah milik Muhammadiyah tidak lagi terjaga, sampai diserobot dan dikuasai oleh oknum yang tidak bertanggung jawab (Dg. Maggading, 1967).
Kondisi ini diperburuk oleh situasi di mana hubungan administrasi organisasi antara ranting dan cabang telah terputus sama sekali, baik cabang terhadap rantingnya maupun sebaliknya. Kesiapan memimpin dan dipimpin telah pudar. Kiai menggambarkan, "Perasaan dipimpin dan memimpin tidak lagi dirasakan. Pimpinan Muhammadiyah Cabang Makassar silih berganti tetapi tidak membawa perubahan-perubahan baru dalam usaha-usaha pergerakan". Lalu ia malanjutkan bahwa yang paling menyedihkan ialah jiwa pembaharu, jiwa reformasi, jiwa revolusioner yang pernah ditanamkan oleh pimpinan-pimpinan Muhammdiyah terdahulu kembali menjadi kabur. Amal-amal serta itikad sebagian besar dari para anggota Muhammadiyah terutama Aisyiyah telah banyak bercampur dengan bidah, khurafat, bahkan syirik. Konsekuensinya, Muhammadiyah tidak mampu lagi memberikan contoh menegakkan Islam yang murni, terus berkompromi dengan ahli-ahli bidah dan khurafat.

Kenyataan-kenyataan di atas itulah yang memunculkan keprihatinan K.H. Fathul Mu'in dan mendorongnya untuk kembali mencurahkan pikiran dan tenaga kepada pergerakan Muhammadiyah khususnya di Cabang Makassar dengan daerah kerja meliputi Kotamadya Makassar dan Kabupaten Maros yang terdiri atas 16 ranting yang sebagian besarnya telah ditingkatkan menjadi cabang. Dengan taufik Allah, dalam Rapat Anggota tanggal 7 Februari 1960, K.H. Fathul Mu'in bersama Ustaz Abd. Rahman Thahir dipilih secara aklamasi untuk memegang pimpinan Muhammadiyah Cabang Makassar. Sayang sekali bahwa almarhum Kiai Abd. 
Rahman Thahir belum sempat menjalankan kepemimpinannya, telah dipanggil Allah untuk selama-lamanya (wafat) (Dg. Maggading, 1967).

\section{Langkah Strategis Muhammadiyah Cabang Makassar}

Kondisi umat sangat memprihatinkan, berbagai lini kehidupan dari akidah, muamalah dan akhlak mengalami degradasi yang sangat parah. Keyataan ini menuntut K.H. Fathul Mu'in sebagai pempinan Cabang Muhammadiyah Makassar harus melakukan beberapa langkah strategis sebagai upaya perbaikan di tengahtengah umat. Di antara langkah yang dilakukan untuk mengembalikan umat kepada khittah-nya adalah:

\section{Konsolidasi}

Konsolidasi adalah upaya yang dilakukan untuk memperkuat dan memperteguh kebersamaan. Pada awal kepemimpinan K.H. Fahtul Mu'in Dg. Maggading, konsolidasi ini ditempuh dengan beberapa tahap (Dg. Maggading, 1967):

Pertama, memaksimalkan peran masjid. Tahap pertama yang dilakukan oleh organisasi Muhammadiyah Cabang Makassar adalah dengan cara menghimpun dan menggerakkan massa. Untuk itu, diperlukan adanya markaz (pusat) penggemblengan dan pengaderan sebagai pusat pergerakan. Dengan alasan inilah, pada tanggal 15 Februari 1960 diputuskan untuk kembali membuka Ta'mirul Masajid sebagai salah satu tempat melaksanakan salat Jumat. Keputusan ini kemudian mendapatkan tantangan yang luar biasa dari berbagai kalangan karena dianggap membuka tempat baru untuk berkumpul melaksanakan salat Jumat yang dianggap sama saja dengan memecah belah umat Islam. Hal ini karena sebelumnya telah dibuat sebuah keputusan bahwa seluruh kegiatan Jum'at hanya dilaksanakan di Masjid Raya Makassar.

Walaupun mendapatkan kritikan dari berbagai kalangan karena dianggap membuat perpecahan di tengah umat, bagi kiai keputusan ini sudah final yang tidak bisa lagi ditawar. Fungsi masjid harus kembali dihidupkan agar umat semakin tercerahkan. Melihat kegigihan dan hasil positif yang didapatkan dengan terbukanya Masjid Ta'mirul Masajid, maka langkah ini diikuti oleh berbagai masjid yang pada akhirnya menjadi sebab terbukanya berbagai masjid sebagai tempat melaksanakan ibadah salat Jumat di kota Makassar.

Kedua, kebijakan pimpinan cabang makasar yang mewajibkan seluruh pengurus cabang dan ranting untuk hadir melaksanakan salat Jumat di Ta'mirul Masajid. Kebijakan ini bertujuan agar seluruh anggota mudah menerima instruksiinstruksi indoktrinasi dan pelaksanaan musyawarah-musyawarah rutin. Tahapan ini terasa melelahkan karena berupaya membangun kembali semangat yang selama ini telah pudar. Menurut kiai, yang paling banyak menghabiskan waktu dalam konsolidasi tahap awal ini adalah karena banyaknya rapat anggota. Rapat pengurus terhitung selama tiga bulan pertama pada tahun 1960, terlaksana sebanyak 83 kali siding, yang berarti bahwa sidang konsolidasi dilakukan hampir setiap hari.

Ketiga, fokus pada proses Pendidikan. di mana pimpinan melakukan perbaikan pendidik- 
an secara menyeluruh, mulai dari alat pengajaran, bahan-bahan pelajaran, gaji guru, metode dan sistem, secara radikal mengalami perubahan. Gaji guru dilipatgandakan, sementara uang muka, iuran sekolah, dan buku-buku pelajaran agama dan bahasa Arab, seluruhnya digratiskan. Semuanya ditopang dengan semakin intensnya media informasi mengedukasi masyarakat akan pentingnya pendidikan dan pelajaran agama. Alhasil, banjirlah pelajar yang masuk ke sekolah Muallimin mulai dari kelas Ibtidaiah, bahkan umumnya di semua sekolah yang langsung di bawah naungan Muhammadiyah Cabang Makassar. Pada fase ini, sekolah-sekolah Muhammadiyah penuh sesak karena banyaknya pelajar yang mendaftarkan dirinya untuk bersekolah di institusi-institusi pendidikan Muhammadiyah.

Selain masalah pendidikan, di antara perkara penting yang menjadi fokus perhatian pimpinan Muhammadiyah pada fase ini, yang juga didukung oleh masyarakat umum yang paham agama adalah perlawanan terhadap politik kristenisasi yang masif terjadi.

Keempat, memperkuat bidang dakwah. yang merupakan salah satu inti perjuangan Muhammadiyah. Peran ulama Muhammadiyah sangat signifikan pada fase awal ini, di antaranya yang tidak bisa terlupakan adalah sumbangsih K.H. Djabbar Asyiri yang telah memorsir waktu, tenaga, dan pikirannya untuk pengembangan di bidang dakwah. Pengajian-pengajian mulai digalakkan dan diseberluaskan, khusus untuk kader-kader mubalig dilakukan pertemuan secara berkelanjutan, puluhan bahkan ratusan mubalig terlatih telah dihasilkan dari program ini, di mana mereka merupakan corong-corong dakwah di dalam dan luar Kota Makassar. Pusat gerakan dakwah ini, dimulai dari Masjid Raya Makassar untuk dilanjutkan ke masjid-masjid lainnya. Para khatib dilatih untuk memenuhi kebutuhan masyarakat, mereka dilatih menjadi dai-dai yang andal yang bisa menyesuaikan diri dengan tuntutan zaman.

Kelima, melecutkan peran Aisyiyah. Gerakan Aisyiyah yang sebelumnya melakukan gerakan dakwah khusus yang terbatas hanya untuk pejabat Muhammadiyah yaitu pengajianpengajian yang dipimpin oleh Hadja Hadara Ma'mun Ali mulai meluas dari masjid ke masjid, rumah ke rumah, kampung ke kampung, sampai menyebar ke seluruh kota.

Keenam, popularitas Muhammadiyah dan penggemlengan. dengan dihidupkannya kembali gerakan kepanduan Hizbul Wathan. Yang banyak berjasa dalam hal ini adalah Abd. Hakim S., seorang murid Muallimin yang ketika itu telah berpangkat kapten Angkatan Laut.

Ketujuh, gerakan pemudi yang bergabung dalam Nasyatul Aisyiyah (NA). Setelah melihat aktivitas dari kalangan senior, mereka pun menyingsingkan lengan baju untuk turut melakukan perjuangan. Semboyan perjuangannya adalah al-Birru li Manittaqa' (kebaikan itu hanya milik orang-orang yang bertakwa). Dengan ini tampaklah bahwa seluruh bagian organisasi Muhammadiyah di berbagai segi dan aspek kehidupan umat telah mulai hidup dan berjalan dengan baik, saatnya organisasi melangkah ke fase stabilisasi (Dg. Maggading, 1967).

\section{Stabilisasi}

Setelah proses awal berjalan dengan baik, walaupun tidak bisa dipungkiri masih banyak 
kekurangan-kekurangan yang harus disempurnakan, maka langkah selanjutnya yang dilakukan adalah stabilisasi dengan harapan kondisi yang selama ini terjadi bisa lebih terarah kepada poros perjuangan dan cita-cita organisasi. Oleh sebab itu, dilakukanlah stabilisasi pada beberapa bagian (Dg. Maggading, 1967).

Pertama, stabilisasi aset organisasi. Masa ini dilakukan stabilisasi di berbagai lini kehidupan, mulai dari stabilisasi karena adanya penyelewengan ideologis maupun materil. Fase pertama ini ditandai dengan "penyehatan" kepemilikan organisasi yang dilakukan awal tahun 1961. Tanah wakaf, gedung, alat sekolah yang dimanfaatkan oleh perorangan di beberapa wilayah, seperti Bontoala, Mariso, Wajo, Mamajang, semua dapat diselamatkan. Termasuk di dalamnya, stabilisasi Panti Asuhan Bahagia, sebagai tempat pemeliharaan anakanak yatim berada dalam kondisi yang sangat menyedihkan, anak-anak tidak terurus, pakaian, makanan, kesehatan, pendidikan semuanya tidak didapatkan dengan baik.

Kedua, stabilisasi ideologis. Penyelewengan ideologis banyak terjadi karena kurang berjalannya dakwah dan pengajian. Kondisi ini mengakibatkan anggota dan simpatisan Muhammadiyah banyak yang terlibat perbuatan bid'ah dan khurafat, bahkan sampai pada perbuatan syirik. Melihat kondisi yang sangat menyedihkan ini, dilakukan indoktrinasi penjiwaan ke Muhammadiyaan yang hakekat ajarannya adalah pemurnian dengan cara pengajaran kembali tentang pengertian agama secara massal dan berkelompok. Jika sebelum tahun 1960-an, sangat sulit membedakan antara kalangan Muhammadiyah dengan orang-orang yang taklid, maka pada fase stabilisasi ini tampak tindakan yang ekstrim dari pihak pimpinan Muhammadiyah yang dilancarkan dari Ta'mirul Masaijd di mana setiap Jumat di samping khutbah juga sebelumnya diadakan pengajian yang bersifat penjiwaan dan pembangkitan semangat.

Ketiga, stabilisasi pengaderan. Pada fase ini, tantangan-tantangan yang dihadapi tidaklah ringan, membutuhkan tenaga dan kesungguhan ekstra agar dapat melalui semuanya. Kiai menggambarkan bahwa suatu tantangan yang penuh bahaya untuk dihadapi pada masa ini adalah adanya Nakomisasi Indonesia oleh Sukarno, PKI dan ulama-ulama pencatut agama (ulama yang menjual agamanya untuk kepentingan dunia). Untuk menghalau tersesatnya umat terlalu jauh, kegiatan-kegiatan pengaderan terpaksa dilakukan dengan sembunyi-sembunyi, baik perorangan maupun kelompok. Pimpinan Muhammadiyah Cabang Makassar menyadari bahwa bahaya untuk melawan politik Sukarno dan ulama pengkhianat agama pada 1962-1963 yaitu zaman keemasan Nasakom. Tidak sedikit tenaga dan pikiran yang dikerahkan untuk mengatasi hal ini. Dalam masa ini yaitu akhir 1963 tidak lagi hanya terbatas melakukan clearing/rehabilitasi ideologi atau penjelasan tentang rusaknya ideologi Nasakom tapi sudah sampai pada tahap mengisi jiwa mahasiswa dan pelajar untuk menentang dan melakukan perlawanan terhadap Nasakom. Upaya ini, ditambah dengan pendalaman pemahaman kebobrokan Nasakom, kepalsuan-kepalsuan ajaran Sukarno yang sama sekali tidak bersifat ilmiyah, serta penyelewengan dari garis-garis agama yang dilakukan oleh golongan-golongan Islam yang kerja sama dengan PKI semuanya diungkap. 
Menghidupkan jiwa penentang Nasakom ini tidak hanya dilakukan melalui kuliah-kuliah umum di seluruh kota dan di universitasuniversitas. Bahkan sistem dan konten pelajaranpelajaran (kurikulum) penentangan diatur oleh dosen/sarjana dan ulama anti-Nasakom, di antaranya S. Madjidi, K.H. Abd. Rahman Syihab, dll. Otak dari gerakan ini diatur dan dimulai oleh Latif Masri yang dibantu oleh sarjana lain yang menjabat sebagai rektor Universitas Muhammadiyah Sulseltra. Hasilnya, kiai mengatakan, "Alangkah hebat hasil yang kita peroleh dalam pembangunan jiwa ini. Kesadaran akan bahaya ajaran Nasakom meresap dan menyusup kemana-mana se-Sulseltra." (Dg. Maggading, 1967).

\section{Masa Pembangunan}

Setelah masa konsolidasi dan stabilisasi dinilai sukses, saatnya melangkah ke tingkatan selanjutnya yaitu masa pembangunan. Pada Rapat Pengurus akhir tahun 1962, diputuskan untuk memperluas bidang usaha dan pembangunan Muhammadiyah untuk lebih melengkapi alat-alat pejuangan menghadapi masamasa mendatang. Perluasan dan penyelesaian serta perlengkapan Ta'mirul Masajid diintensifkan. Dalam masa ini, terbangunlah: Gedung Perpustakaan, Gedung Musafir, dan Gedung Kuliah. Seluruh usaha pembangunan ini, dapat dirampungkan pada tahun 1963.

Selain itu, pengumpulan kekuatan baru untuk membangun dan membuka rumah bersalin St. Khadijah terus diusahakan. Cita-cita ini tidaklah mudah. Untuk mewujdukan harapan, seluruh personil yang masuk dalam tim pembangunan, menurut kiai, haruslah diambil dari tenaga-tenaga cakap dan revolusioner. Anggota panitianya diketuai oleh Overta Yasin Limpo yang terdiri dari orang tua kawakan dalam Muhammadiyah, didampingi tenaga-tenaga muda yang berani berkorban. Setelah perjuangan panjang, akhirnya pada November 1963, citacita yang selama puluhan tahun itu bisa terealisasikan.

Selangkah demi selangkah, bertambahlah usaha Muhammadiyah Cabang Makassar. Langkah dan darmanya ini diikuti oleh cabangcabang lain di seluruh Sulseltra yang pada akhir 1966, kedudukan dan status disesuaikan dengan struktur organisasi Muhammadiyah sekarang.

Pada rentang waktu 1960-1967 dapat dilihat kesungguhan dan keikhlasan para pimpinan organisasi ini melakukan pengorbangan yang baktinya semata-mata karena Allah untuk kepentingan masyarakat. Bahaya telah banyak dilalui, tak terbilang tantangan yang dihadapi, sebagai bukti bahwa bukan kekayaan, bukan pangkat dan jabatan yang diinginkan oleh Kiai sebagai pimpinan Muhammadiyah. Kiai hanya ingin melihat umat Islam hidup, rohani dan jasmaninya, sesuai dengan ajaran Islam yang murni menurut Nabi shalallahu 'alaihi wasallam, panduannya hanya dari Allah dan Rasul-Nya. Bukan kepada pendeta sebagaimana Yahudi dan umat Kristen, bukan pula sebagai pentaklid pengekor ulama, karena hanya kepada Allah dan Rasul tempat kita kembali dalam segala masalah. Fungsi ulama hanya mengajar, pemberi keterangan. Kedudukan ulama, guru, sarjana, rakyat sama dalam ikatan, yaitu semua hanya wajib ikut pada Allah dan Rasulullah. 
Penjelasan ini ditutup oleh Kiai Fathul Mu'in dengan potongan kalimat yang menunjukkan betapa sulit jalan yang telah dilalui untuk sampai pada harapan. Kiai mengatakan, "Sebanyak ini yang telah kami kerjakan, lebih banyak pula yang masih tertinggal. Tujuan masih jauh, memerlukan tenaga dan pikiran. Tujuan ini tidak mungkin diusahakan oleh segelintir manusia tetapi harus bersatu, bersama di atas landasan yang satu dan sama yaitu Al-Qur'an dan Sunah. Untuk itu kita semua bertanggung jawab, tidak ada satu pun orang yang diizinkan berpangku tangan. Siapa yang tidak ikut mengatasi kesulitan mengumpulkan dana dan daya untuk menutupi segala kebutuhan umat Islam, maka ia bukanlah golongan kami” (Dg. Maggading, 1967).

\section{Simpulan}

Berdasarkan hasil penelitian dan pembahasan, dapat disimpulkan beberapa hal: Pertama, K.H. Fathul Mu'in Dg. Maggading sebagai Ketua Muhammadiyah Makassar Cabang periode tahun 1960-1966, menghadapi berbagai macam tantangan. Dalam rentang waktu tersebut, K.H. Fathul Mu'in menghadapi tiga tantangan pokok dakwah di awal periode kepemimpinanya: (1) pertumbuhan Gerakan PKI; (2) bubarnya Partai Masyumi; dan (3) kelumpuhan gerakan Muhammadiyah di berbagai lini.

Kedua, kondisi umat yang sangat memprihatinkan di berbagai sisi kehidupan, membuat K.H. Fathul Mu'in sebagai pempinan Cabang Muhammadiyah Makassar melakukan beberapa langkah strategis sebagai upaya perbaikan di tengah-tengah umat, yaitu: (1) konsolidasi, yakni dengan memaksimalkan peran masjid, mewajib- kan seluruh pengurus cabang dan ranting untuk hadir melaksanakan salat Jumat di Ta'mirul Masajid, fokus pada proses pendidikan, memperkuat bidang dakwah yang merupakan salah satu inti perjuangan Muhammadiyah, melecutkan peran Aisyiyah, popularisasi Muhammadiyah dan penggemblengan semangat kader menggiatkan gerakan Nasyatul Aisyiyah (NA); (2) stabilisasi, yakni dengan stabilisasi aset organisasi, stabilisasi ideologis, dan stabilisasi pengaderan; (3) menggalakkan pembangunan, yakni dengan memperluas bidang usaha dan pembangunan Muhammadiyah untuk lebih melengkapi alat-alat pejuangan menghadapi masa-masa mendatang. [k]

\section{Daftar Pustaka}

Abbas, J., Aman, J., Nurunnabi, M., \& Bano, S. (2019). The Impact of Social Media on Learning Behavior for Sustainable Education: Evidence of Students from Selected Universities in Pakistan. Sustainability, 11(6), 1683. https://doi.org/10.3390/ su11061683

Adiansah, W., Mulyana, N., \& Fedryansyah, M. (2016). Potensi Crowdfunding di Indonesia dalam Praktik Pekerjaan Sosial. Prosiding Penelitian dan Pengabdian Kepada Masyarakat. https://doi.org/ 10.24198/jppm.v3i2.13655

Ahmad, T. (2008). Kamp Pengasingan Moncongloe. Desantara.

Alwi, M. (n.d.). Gerakan Dakwah Muhammadiyah di Sulawesi Selatan. Jurnal Diskursus Islam, 2013(1).

Arif, A., U., P., \& Bosra, M. (2016). Muhammadiyah di Kabupaten Soppeng 1930-1985. 
Pattingalloang: Jurnal Pemikiran Pendidikan dan Penelitian Kesejarahan, 3(4), 1-10.

Bosra, M. (2008). Tuan Guru, Anrong Guru dan Daeng Guru: Gerakan Islam di Sulawesi Selatan 1914-1942. Makassar: La Galigo Press.

Bosra, M. (Ed.). (2015). Menapak Jejak: Sejarah Gerakan dan Biografi Ketua-ketua Muhammadiyah Sulawesi Selatan. Yogyakarta: Suara Muhammadiyah.

Chakim, S. (2017). Kontestasi Kuasa atas UndangUndang Produk Tembakau di Media (Undang-Undang Nomor: 36 Tahun 2009). Komunika: Jurnal Dakwah dan Komunikasi, 9(2), 302-324. https://doi.org/10.24090/ komunika.v9i2.855

Creswell, J. W. (2010). Research Design: Pendekatan Kualitatif, Kuantitatif, dan Mixed (A. Fawaid (Trans.); 3rd ed.). Yogyakarta: Pustaka Pelajar.

Darmawijaya. (2007). Sejarah Muhammadiyah di Makassar. Makassar: Pustaka Refleksi.

Darmawijaya, D., \& Abbas, I. (2014). Sejarah Muhammadiyah di Sulawesi Selatan 1926-1942. Jurnal Lektur Keagamaan, 12(2), 465-478.

Dg. Maggading, F. M. (1967). Beginilah Muhammadijah Langkah dan Dharma Bakti Muhammadijah Tjab. In Makassar 19601966. Makassar: t.p.

Elhady, A. (2017). Islamic reform movement in Indonesia: role of Muhammadiyah in social empowerment. International Journal of Academic Research in Business and Social Sciences, 7(8), 340-350.

Fherastama S, Y., Fitrianita, T., \& Nugroho, A. B. (2018). Kontestasi Organisasi Mahasiswa Ekstra Kampus di Lembaga Dakwah Kampus Universitas Brawijaya. Jurnal Kajian
Ruang Sosial-Budaya, 2(2), 70-91. https:// doi.org/10.21776/ub.sosiologi.jkrsb.2018. 002.2 .06

Hamid, I., Jalaluddin, F., \& dkk. (2015). Matahari Pembaharuan di Serambi Madinah Menelusuri tapak sejarah Muhammadiyah Kota Makassar. Makassar: Majelis Pustaka PDM Kota Makassar \& LSQ Makassar.

Handayani, F., \& Bosra, M. (2019). Legalisasi Lotto di Makassar, 1967-1969. Pattingalloang: Jurnal Pemikiran Pendidikan dan Penelitian Kesejarahan, 6(2), 35-45. https://doi.org/ 10.26858/pattingalloang.v6i2.10823

Haryanto, S. (2017). Pendekatan Historis Dalam Studi Islam. Jurnal Ilmiah Studi Islam, 17(1), 127-135.

Huda, M. S. (2019). The local construction of religious blasphemy in East Java. Journal of Indonesian Islam. https://doi.org/ 10.15642/JIIS.2019.13.1.96-114

Noer, D. (1996). Gerakan Modern Islam di Indonesia 1900-1942. LP3ES.

Nursalam, S. (2017). Interaksi Keberagamaan Muhammadiyah di Makassar. Jurnal Equilibrium Pendidikan Sosiologi, V(2).

Pasha, M. K., \& Darban, A. A. (2000). Muhammadiyah sebagai Gerakan Islam: Dalam perspektif historis dan ideologis. LPPI.

Ramly, A. M., \& dkk. (2006). Demi Ayat. Tuhan, Upaya KPPSI Menegakkan Syariat Islam. OPSI.

Rifa'i, M. (2018). Kajian Masyarakat Beragama Perspektif Pendekatan Sosiologis. AlTadzim: Jurnal Manajemen Pendidikan Islam, 2(1), 23-35.

Risfaisal, S., \& Rosnatang. (2017). Gerakan Sosial Muhammadiyah di Era Modernisasi pada Masyarakat Masserempulu Kabupaten 
Enrekang. In Prosiding Seminar Nasional Himpunan Sarjana Ilmu-ilmu Sosial (Vol. 2).

Rohmatika, R. V. (2019). Pendekatan Interdisipliner dan Multidisipliner dalam Studi Islam. Al-Adyan: Jurnal Studi Lintas Agama, 14(1), 115-132.

Salbu, M. (2012). Mencetak Kader. Lentera Optima Surabaya.

Siregar, I. F. (2013). Sejarah Pertumbuhan dan Perkembangan Partai Masyumi (19451960. Jurnal Thaqafiyyat, 14(1), 91.

Sukarta, S. (2018). Internalisasi Nilai-Nilai Dakwah Multikultural dalam Pembelajaran Al-
Islam di Universitas Muhammadiyah Mataram. Al-I'lam: Jurnal Komunikasi dan Penyiaran Islam. https://doi.org/ 10.31764/jail.v1i2.229

Wildan, M. (2015). Gerakan Islam Kampus: Sejarah dan Dinamika Gerakan Mahasiswa Muslim. In Sejarah Kebudayaan Islam Indonesia (3rd ed., pp. 425-461). Jakarta: Direktorat Sejarah dan Nilai Budaya, Direktorat Jenderal Kebudayaan, Kementerian Pendidikan dan Kebudayaan. 